\title{
Legislative process in the field of ethnological expert examination in Russia
}

\author{
Antonina Gorbunova ${ }^{1}$, Maksim Zadorin ${ }^{2,}$, and Nikita Kuprikov ${ }^{3}$ \\ ${ }^{1}$ Interregional Public Organization "Union of Small-Numbered Peoples "Alliance"”, 647000 2A 40 \\ Let Pobedy Ulitsa, apart. 38, Dudinka, Russia \\ ${ }^{2}$ Northern (Arctic) Federal University named after M.V. Lomonosov, 16300059 Lomonosov \\ Prospekt, Arkhangelsk, Russia, \\ ${ }^{3}$ Scientific and Information Center "Polar Initiative", 1250801 Volokolamskoe Shosse, Moscow, \\ Russia; Moscow Aviation Institute (National Research University), 1250804 Volokolamskoe Shosse, \\ Moscow, Russia
}

\begin{abstract}
The article analyses the stages and peculiarities of development of ethnological expert examination as an institution in the Russian Federation. It is beyond argument that different actors to various extent involved in the implementation of the project in question, adhere to divergent approaches, namely: from defining the key regulatory authority (federal center or regions), correlation between ethnological and ecological expert examinations, social and technocratic approaches to the territory development and the role of indigenous small-numbered peoples. Pursuant to the strategic planning documents, ethnological expert examination represents a tool for implementation of the Russian state policy regarding different nationalities. However, state-recognized ethnological expert examination with all legal consequences it entails is only pursued in the Sakha Republic (Yakutia) based upon a regional law. The federal legislator only provides a definition of ethnological expert examination (scientific research into the influence of changes in the original living environment of indigenous small-numbered peoples and sociocultural situation on the development of an ethnic group) without enacting any statutory instrument to regulate the procedure. The analysis has shown that Russian legislation requires statutorization of the ethnological expert examination procedure and its binding character along with elaboration of conceptual framework, subject matter and object of this research.
\end{abstract}

\section{Introduction}

The problematics relating to the ethnological expert examination has for a long time been imminent in the Russian society. The issue of importance and correlation between business-driven projects (for instance, there are currently 15 infrastructure projects planned for implementation on the territory of the Sakha Republic (Yakutia), which are bound to influence the quality of ecosystem (Burtseva et al. (2020)) and everyday life of smallnumbered indigenous communities in the north shall be resolved by means of finding a

\footnotetext{
*Corresponding author: m.zadorin@narfu.ru
} 
compromise and science-based approach involving the assessment of the project impact on the very essence of existence of locally homogeneous ethnic groups vested with constitutional safeguards as aboriginal inhabitants of the north. The Arctic economy demands innovative decisions, yet practical experience demonstrates that public authorities and businesses focus their activities on optimization and investment raising, including creation of the so-called stronghold areas, special tax regimes, etc. (Kudryashova et al. (2019)). Against this background, the issue of ethnological expert examination is left unaddressed. There is no doubt that this fact shall further contribute to the negative trend when describing the ethnosocial and ethnocultural space of the north, inevitably resulting in unsustainable ethnodemographical profile in the context of general population outflow (Khoreva et al. (2018)). Within the framework of this mini-research, the authors attempt to consider a number of crucial issues associated with legislative evolution of ethnological expert examination, regional initiatives and nationwide concept of sustainable development, as well as with the experience of the Yakutia legislator and judiciary, and the assessment of role played by the Federal Agency for Ethnic Affairs in this issue. In conclusion, the authors emphasize the importance of distinction between the procedures of ethnological expert examination taking place prior to any industrial or commercial development and after a technological incident in an area of original dwelling and traditional economic activities of indigenous small-numbered peoples.

\section{Problem Statement}

\subsection{The concept of ethnological expert examination at an early stage of its existence}

At the time it was passing the first reading in the State Duma of the Russian Federation Federal Assembly on October 09, 1998 (draft law No.97802467-2), the Federal Law No. 82-FZ as of April 30, 1999, On Guarantees of the Rights of Indigenous Small-Numbered Peoples of the Russian Federation, treated ethnological expert examination as science-based study or research into the influence of the original living environment on the development of an ethnic group. Later on, at the second reading on February 17, 1999, ethnological expert examination was defined in the law as scientific research into the influence of changes in the original living environment of indigenous small-numbered peoples, sociocultural situation on the development of an ethnic group. The final text of the law adopted by the Russian Parliament construes ethnological expert examination as a scientific research into the influence of changes in the original living environment of indigenous small-numbered peoples of the Russian Federation and sociocultural situation on the development of an ethnic group.

Such transformation of the definition indicates, firstly, that ethnological expert examination: - has always been primarily regarded as scientific research; - and secondly, that the legislator expects ethnological expert examination to research into the original living environment along with the sociocultural situation pertaining to indigenous smallnumbered peoples.

\subsection{Regional initiatives, sustainable development concept and the Yakutia precedent}

Between 2004 and 2006, the legislative bodies of three Russian Federation regions (Nenets Autonomous Area Council of Deputies (draft law No. 63519-4), Yamalo-Nenets Autonomous Area State Duma (No. 146315-4), and Sakhalin Regional Duma (No. 353031- 
4)) introduced in the Russian parliament three draft laws with a common objective: incorporation of ethnological expert examination into ecological expert examination (in the areas of original dwelling and traditional economic activities of indigenous small-numbered peoples). All draft laws were rejected mainly on the basis of argument that ecological and ethnological expert examinations pursue different aims. For instance, ecological expert examination is held in order to prove compliance of intended economic and other activities with environmental requirements. When these draft laws were under consideration, it was oftentimes mentioned that a separate statutory instrument shall be developed to regulate the issue of ethnological expert examination.

In 2009, the Russian Government adopted a new landmark strategic document called The Concept of Sustainable Development of Indigenous Small-Numbered Peoples of the North, Siberia and Far East of the Russian Federation (Decree No. 132-p as of February 04, 2009). The declared objective of the Concept is setting the national stage for securing sustainable development of indigenous small-numbered peoples of the North, Siberia and Far East in reliance upon strengthening their socioeconomic potential while at the same time preserving these peoples' original living environment, traditional lifestyle and cultural values. In order to achieve this objective, it necessary to resolve a number of tasks also specified in the Concept. The first task is preservation of the original living environment and traditional use of natural resources necessary for safeguarding and fostering the traditional way of life led by the indigenous small-numbered peoples of the North, Siberia and Far East. As a solution to this task, the Concept provides for establishing the procedure and methods of ethnological expert examination in the areas of original dwelling and traditional economic activities of indigenous small-numbered peoples of the North, Siberia and Far East. However, the above-mentioned provisions have not yet been developed any further from the legislative point of view.

Alongside this, there is one region, namely the Sakha Republic (Yakutia), where the law on ethnological expert examination has been effective for 10 years (820-Z No. 537-IV adopted on April 14, 2010 (as amended on January 30, 2019)) allowing this region to accumulate the unique law-making and law-enforcing experience (scheme of application fig 1.). Over this period, 22 ethnological expert examinations were carried out in the Republic.

The authorized authority is the Ministry for Arctic Development and Northern Peoples' Affairs.

Consumers of ethnological expert examination services are legal entities or individuals intending to conduct economic activities across 21 Republican districts as areas of original dwelling and traditional economic activities of indigenous small-numbered peoples.

The concept of economic and other activities is basically very broad, and pursuant to the Law it relates to any potential impact on the living environment and sociocultural situation in the areas inhabited by indigenous peoples.

The Republican budget covers expenses for expert examination provided that the consumer paid a fee in the amount calculated based upon the scope of expert work. The expert examination procedure is regarded in the Republic as a public service in accordance with the administrative regulations.

The consumer submits an application for expert examination to the Ministry along with the project documents and a set of materials on the ethnoecological expert examination. According to the official Ministry website, the parties execute an agreement on ethnological expert examination of the project documents following preliminary inspection of submitted materials. It should be noted that the regional Law itself defines the following as research objects: project documents, statutory instruments, indigenous peoples and their original living environment, sociocultural situation in the area of potential implementation of an economic (infrastructural, industrial, etc.) project. 
Pursuant to the approved procedure, a set of materials on the ethnoecological impact assessment shall comprise 10 items, among which there are common features of ethnocultural landscape in the area intended for development, as well as estimates of damage incurred by indigenous people, including identification and measurement of the following target values at the regional and local levels: annual gross income generated from traditional economic activities; amount of stakeholder's loss of profit in the areas of environmental disturbance; amount of stakeholder's loss in case of land condemnation or assignment of land or other natural resources for permanent use; amount of stakeholder's loss caused by degradation of land or depletion of natural resources due to intended economic and other activities (including land contamination); amount of stakeholder's loss due to encumbrances imposed on land plots.

The consumer can prepare the above-mentioned materials independently or using the assistance of research and expert organizations. The aforesaid materials shall not be made available to the public. Within three months, a team of experts shall conduct an applied interdisciplinary research of the materials submitted by the consumer.

A team of experts to conduct the expert examination shall be appointed by the authorized body upon the results of the procurement procedure in accordance with the Federal Law as of April 05, 2013, No. 44-FZ On the Contract System for the Purposes of State and Municipal Procurement of Goods, Work, and Services. According to Sleptsov (2017), a team of experts usually comprises the following research scientists: lawyer, economist, ethnologist, sociologist, biologist with expertise in the field of traditional types of economic activities carried out by indigenous small-numbered peoples. Other experts may render their services if necessary. As a result of the procedure, a team of experts produces an opinion, which is considered by the Expert Commission. Following this consideration, the executive secretary prepares a draft negative or positive decision.

The Expert Commission is formed to function permanently, its personal composition being approved by the Decree of the Sakha Republic (Yakutia) Government (as of October 30, 2015, No. 1228-p (as amended on March 25, 2020)), and its activities set forth in the Regulation approved by the Republican Government Decree (as of September 06, 2011, No. 428). It is worth mentioning that alongside the Republican First Deputy Prime Minister, Republican Minister for Arctic Development and Northern Peoples' Affairs, Head of Department for the Northern Peoples' Affairs, Legal and Ethnological Expert Examination, the Commission also comprises representatives of indigenous peoples. However, Sleptsov, Petrova (2019) emphasize that Russia does not have a separate law regulating free, prior and informed consent (FPIC). Informed consent of the northern peoples during expert examination is nevertheless manifested in the minutes of their general meeting, where business representatives make them familiar with the project, and experts report on the results. The findings of scientific research into the impact of any industrial project on the northern peoples along with the opinion of the same peoples are registered in the form of an open vote on whether giving or withholding consent for the industrial development of areas of traditional industrial activities conducted by indigenous inhabitants (also known as traditional nature management areas), which is an integral part of ethnological expert examination.

The expert commission opinion based upon the results of an ethnological expert examination attains its status after being approved by the Republican Government. All 22 ethnological expert examination procedures resulted in the approval of affirmative opinions, and the total amount of paid damages (with regard to 18 ethnological expert examinations) is 103 million Rubles in contrast to the estimated amount of 496 million Rubles.

Communities of indigenous small-numbered peoples, peasant (farm) households, agricultural consumer cooperatives, municipal unitary enterprises and joint-stock 
companies are all recipients of damages subsequent to ethnological expert examinations conducted. It should be noted that damages are paid immediately to the landholders, and the amount of loss is calculated pursuant to the Procedure approved by the valid decree of currently non-existing Ministry of Regional Development (as of December 09, 2009, No. 565).

According to Burtseva и Bysyina (2019), а major challenge in this situation is associated with the current Procedure of calculating losses of indigenous peoples, since it only provides for the loss of biological resources used by these peoples without giving consideration to ethnocultural and social phenomena, such as language, culture, lifestyle. As noted by Gassiy и Potravny (2019), the assessment of an industrial enterprise's impact on the ecosystem and ethnocultural development of indigenous peoples shall reconsider the methods used to calculate losses from traditional nature management, which are currently based upon the rates describing the loss of income from traditional nature management. These methods shall be amended to include ecological and socioeconomic expenses to be additionally covered by the mine owners in order to improve the living conditions of indigenous peoples (creation of new jobs, education expenses, change of lifestyle, etc.).

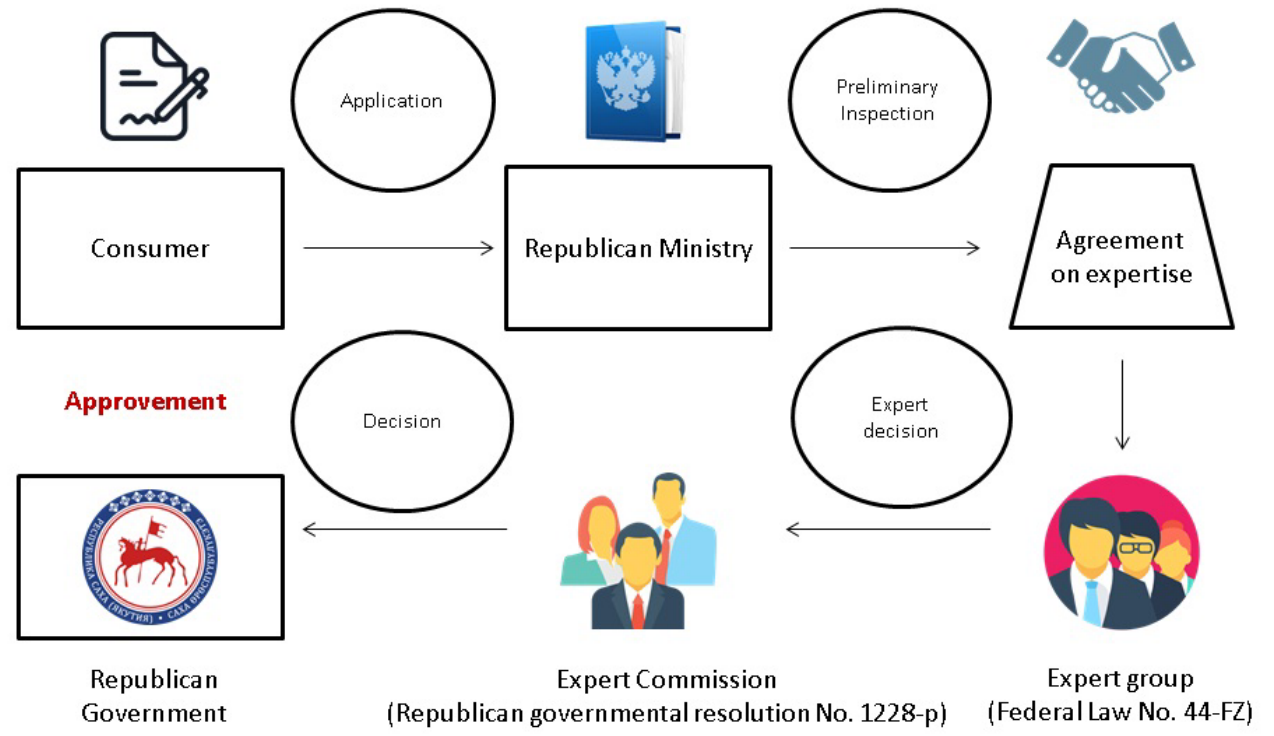

Fig. 1. Scheme of ethnological expert examination in the Republic of Sakha (Yakutia).

\subsection{Federal Agency for Ethnic Affairs Project: under development}

On October 31, 2016, following the session of the Interethnic Relations Council devoted to the urgent issues of implementation of the state Strategy regarding different nationalities, the Russian President instructed the Government to cooperate with the regional executive authorities on the issue of statutorization of the ethnological expert examination procedure and to submit their proposals on the matter until October 01, 2017.

In furtherance of Clause 3 of the President's List of Instructions given as a result of the Council for Interethnic Relations session as of December 04, 2016, No. Pr-2338, the Federal Agency for Ethnic Affairs (FADN) prepared and published a draft federal law On Ethnological Expert Examination in the Russian Federation on the federal portal of draft statutory instruments (ID 01/05/01-18/00077915). This draft law suggested to codify a definition of ethnological expert examination as assessment of sociocultural consequences of introduced economic activities and other managerial decisions for the sites of 
ethnocultural heritage of the Russian Federation citizens. With regard to the above, the sites of ethnocultural heritage of the Russian Federation citizens were treated as intangible cultural heritage of the Russian Federation citizens.

The concepts, principles and implementation tools referred to in the text of this draft federal law were not relevant to the intended stakeholders, and primarily to the indigenous small-numbered peoples. While proposing the assessment of economic activities impact on the sites of ethnocultural heritage of the Russian Federation citizens (intangible cultural heritage), the authors of the legislative initiative disregarded the impact of economic activities on the original living environment, traditional lifestyle and traditional economic activities of indigenous small-numbered peoples as an object of assessment.

Moreover, the experts highlighted the following: - almost all powers relating to the ethnological expert examination were to be delegated to the Russian Government and beyond reach of any regional authorities; - no provision was made for the public control; expert examination assessment powers exercised by the representatives of indigenous small-numbered peoples were not specified, and expert examination itself was not in any manner balanced against the existing historical and cultural expert examination.

This legislative initiative was preceded by the analytical report by the Institute of Ethnology and Anthropology named after N.N. Miklukho-Maklai at the Russian Academy of Sciences (IEA RAS) prepared in 2017 as part of the public contract on providing services of expert and analytical studies on the following subject: Development of proposals for statutorization of ethnological expert examination as an institution in the Russian Federation for the purposes of safeguarding rights and protecting interests of indigenous small-numbered peoples of the North, Siberia and Far East against the background of industrial development in the areas of their residence and traditional lifestyle. The conclusion to this report recommended ethnological expert examination of activities affecting ethnocultural interests of citizens, communities and other actors. It was also noted that ethnological expert examination shall result in the assessment of these projects' impact on the sites of ethnocultural heritage. It was proposed to specify a list of such sites in specialized registers. In summary, it was pointed out as follows:

Thus, statutorization of ethnological expert examination can implement an effective and flexible mechanism of government regulation aimed at preservation of society-accumulated cultural and intellectual values, historical continuity, historical memory and spiritual connection between generations, as well as at support and strengthening of common cultural space within the country, consideration of cultural interests and needs of indigenous small-numbered peoples and all other citizen groups in the Russian Federation.

In 2018, the Federal Agency for Ethnic Affairs made an attempt to execute the Russian President's Instruction concerning statutorization of ethnological expert examination procedure. The legislative initiative in question consisted in making amendments to the current Federal Law as of April 30, 1999, No. 82-FZ, rather than introducing a separate federal law. The draft federal law (ID: 01/05/12-18/00086735) intended to conduct ethnological expert examination when developing state programs of the Russian Federation and regional state programs relating to exploration of natural resources and environmental protection in the areas of original dwelling and traditional economic activities of indigenous small-numbered peoples. During finalization of the said statutory instrument, it was proposed to extend ethnological expert examination to the strategic planning documents to be implemented in the areas of original dwelling and traditional economic activities of indigenous small-numbered peoples. Therewith, the draft stipulated that the Russian Government shall exclusively decide on the following: - procedure of ethnological expert examination; - list of strategic planning documents, which development and alteration require ethnological expert examination; - scientific institution authorized to conduct ethnological expert examination. 
The proposed concept could be basically reasonable considering that strategic planning documents are developed as part of goal-setting, forecasting, planning and programming on a federal level, as well as on the level of the Russian Federation regions and municipalities. Alongside this, however, the authors of this legislative initiative ignore potential man-made emergencies requiring expert research, such as Norilsk oil spill.

\section{Findings}

1. In reliance upon the analysis conducted, it can be concluded that ethnological expert examination is an applied interdisciplinary research across various scientific disciplines. Exact disciplines falling within the range of ethnological expert examination as scientific research are mainly determined by the objectives and tasks the expert examination intends to accomplish. For instance, one crucial point is whether or not this ethnological expert examination extends to the actual oil spill (i.e. the fact of immediate damage to the original living environment - not just intended economic activity). According to the authors, in case of an accomplished man-made emergency it is necessary to take the following actions in a stepwise manner:

1) determine the borders of the pollution area inhabited by indigenous peoples leading their traditional lifestyle and traditional economic activities;

2) keep record of any changes in the original living environment;

3) identify the stakeholders eligible for damages;

4) specify the types of traditional economic activities affected by the pollution;

5) assess the impact of changes in the original living environment on the traditional lifestyle and traditional economic activities of specific groups of people and associations;

6) develop a set of recommended measures aimed at reduction and remediation of negative impact on traditional economic activities and lifestyle of indigenous peoples.

2. Conceptual task set by the federal government is to preserve the original living environment and traditional use of natural resources necessary for safeguarding and fostering the traditional way of life led by the indigenous small-numbered peoples of the North, Siberia and Far East. In order to tackle this task in the longer term, the government forecasts to specify the procedure and methods of ethnological expert examination.

3. Ethnological expert examination has been conducted in the Sakha Republic (Yakutia) for more than 10 years following a strictly regulated procedure and involving the indigenous peoples' communities in the expert work, where their opinion is subject to mandatory record-keeping, thus allowing actual implementation of the free, prior and informed consent concept (given the fact that there is no separate federal law to regulate the issue).

4. The basic idea promoted by the Federal Agency for Ethnic Affairs is to delegate the wide-ranging set of powers to the federal government, including the authority to decide upon: the procedure of ethnological expert examination; the list of strategic planning documents, which development and alteration require ethnological expert examination; as well as the scientific institution authorized to conduct ethnological expert examination.

\section{Conclusion}

Pursuant to the strategic planning documents, ethnological expert examination represents a tool for implementation of the Russian state policy regarding different nationalities. On the one hand, the non-availability of institutionalized procedure of ethnological expert examination provides space and opportunity to apply flexible approaches to this research allowing it to consider regional peculiarities (in this particular case, also the actual 
emergency situation (Norilsk oil spill case). On the other hand, it preconditions the publiccontrolled status of this expert examination and optionality in enforcing its recommendations.

With regard to the Russian legal environment, expert examinations are usually conducted to show compliance with technical standards, statutory requirements, etc. This is one of the reasons behind the failure of idea to conduct ethnological expert examination as part of ecological expert examination. The analysis has shown that Russian legislation requires statutorization of the ethnological expert examination procedure and its binding character along with elaboration of conceptual framework, subject matter and object of research.

\section{References}

1. E. Burtseva, A. Bysyina, Resources 8(1).55, 1-14 (2019)

2. E. Burtseva, A. Sleptsov, A. Bysyina, A. Fedorova, G. Dyachkovskii, Resources 9(95), 1-19 (2020)

3. V. Gassiy, I. Potravny, Resources 8(71), 1-19 (2019)

4. O. Khoreva, R. Konchakov, C.S. Leonard, A. Tamitskiy, K. Zaikov, Polar Record 54(5-6), 324-338 (2018)

5. E.V. Kudryashova, S.A. Lipina, K.S. Zaikov, L.K. Bocharova, A.V. Lipina, M.Yu. Kuprikov, N.M. Kuprikov, The Polar Journal 9(2), 445-458 (2019)

6. G.P. Ledkov, A.I. Gorbunova, M.Yu. Zadorin, Saving the indigenous population in the Arctic zone of the Russian Federation in the conditions of lifestyle transformation and climate change: Conference Proceedings (Arkhangelsk, KIRA Publishing, 2018)

7. M.Yu. Martynova, Analytical Bulletin (State Duma) (2018)

8. A.N. Sleptsov, Jurist Journal 19, 42-46 (2017)

9. A. Sleptsov, A. Petrova, Resources 8(3).123, 1-17 (2019) 